\title{
Encapsulation in the Food Industry: A Brief Historical Overview to Recent Developments
}

\author{
Yakindra Prasad Timilsena ${ }^{1^{*}}$, Md. Amdadul Haque ${ }^{2 * \#}$, Benu Adhikari $^{3}$ \\ ${ }^{1} \mathrm{Nu}$-Mega Ingredients Pty Ltd., Melbourne, Australia \\ ${ }^{2}$ Department of Agro-Processing, Bangabandhu Sheikh Mujibur Rahman Agricultural University, Gazipur, Bangladesh \\ ${ }^{3}$ School of Science, RMIT University, Melbourne, Australia \\ Email: "mahaque@bsmrau.edu.bd
}

How to cite this paper: Timilsena, Y.P., Haque, Md.A. and Adhikari, B. (2020) Encapsulation in the Food Industry: A Brief Historical Overview to Recent Developments. Food and Nutrition Sciences, 11, 481-508.

https://doi.org/10.4236/fns.2020.116035

Received: May 19, 2020

Accepted: June 14, 2020

Published: June 17, 2020

Copyright $\odot 2020$ by author(s) and Scientific Research Publishing Inc. This work is licensed under the Creative Commons Attribution International License (CC BY 4.0).

http://creativecommons.org/licenses/by/4.0/

(c) (i) Open Access

\begin{abstract}
Encapsulation in food industry serves several functions including masking of undesirable color/flavor/taste, preservation of unstable constituents, incorporation of additional functional and nutritional components and site-specific release of encapsulated ingredients at a controlled time and rate. The knowledge of microencapsulation in other sectors like pharmaceutical industry is well advanced; however, more understanding is required to harvest the maximum benefits from food industry. This paper started with highlighting the gradual progress of microencapsulation process in food industry and ended up with some invaluable suggestions for future works. In the body, the paper reviews the major techniques of food encapsulation, choices of coating materials and the performance measurement methods of food encapsulation. Future trends, scopes and aspects of microencapsulation process in food manufacturing sector are also presented as the necessary recommendations for future researches. The article would help the microencapsulated food manufacturers to choose the target oriented encapsulates and suitable encapsulation technique.
\end{abstract}

\section{Keywords}

Microencapsulation, Shell Materials, Core Materials, Encapsulation Techniques, Encapsulation Efficiency, Controlled Release

\section{Introduction}

Encapsulation is an extensively used technique for designing engineered products in various food industries especially in functional and specialties food

*These authors have contributed equally to this work. 
manufacturing, food processing and product innovation. It involves entrapping a functionally active core material into a matrix of an inert material (Figure 1). The material which is to be encapsulated is known as core or active material. It is also known as fill, internal phase or payload. On the other hand, the material which is used to encapsulate the active ingredient is called coating material, wall, capsule, membrane, shell, matrix or carrier material [1] [2] [3] [4]. The concept of cell encapsulation was discovered first time by [5] [6]. Encapsulation technology was industrially applied first time almost after two decades to obtain pressure-sensitive coatings for the manufacture of carbonless copying paper [7].

Microencapsulation technology received increased interest in industrial application owing to its ability to provide protection to unstable bioactive component, incorporate new functional properties into designed food products and effectively deliver the active material at targeted site at controlled rate. As a consequence, various methods of encapsulation have been explored for a long time. However, the choice of the suitable process varies with the nature of the active ingredient, the properties of the shell material and the desired characteristics of the final product based on the intended use.

In general, food grade proteins and polysaccharides are used to encapsulate sensitive and bioactive food ingredients including highly unsaturated edible oils (e.g. fish oils), vitamins, enzymes or various flavours for enhancing their shelf-life and/or masking the undesirable flavor or taste [8]; however, recent research works focus on enhancing the functionality and health benefits of processed foods and enhancing the efficacy of probiotics and targeted delivery of various enzymes or coenzymes, bioactive peptides and other therapeutic agents [9] [10] [11] [12]. Controlled and sustained release and targeted delivery have been achieved by encapsulating artificial sweeteners, therapeutic proteins and other bioactive ingredients [13] [14] [15] [16]. Although protection of the bioactive ingredients from the environmental stressors (viz. oxygen, radiation, light, moisture and adverse $\mathrm{pH}$ conditions) and controlling the release of actives from the food matrices in the right place at the right time and desired rate are primary

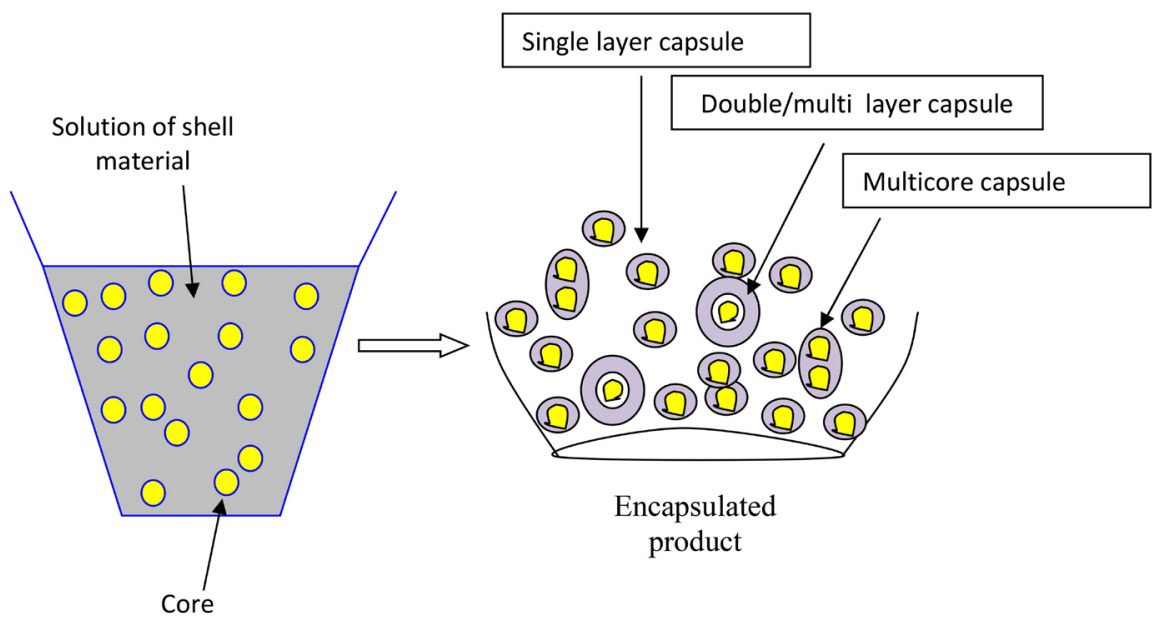

Figure 1. Schematic diagram of encapsulated core in shell material. 
objectives of encapsulation research, recent trends are to improve the product handling in terms of reduced toxicity, reduced cost and enhanced bioavailability of a nutrient. The ultimate objective is to extend product shelf life and improve the overall acceptability of the engineered product [2] [17] [18] [19].

Structural and functional aspects of shell matrices and their compatibility with the core also play vital roles in their efficacy and overall acceptability as encapsulants in food industries. Functional attributes such as solubility, interfacial properties, gelling capacity and economic factors such as cost and availability are some of the important factors to be considered during matrix selection process. In the same way, ability of the shell material to impart the desirable functional properties in the final product is the single-most important factor to be considered. There are several proteins and polysaccharides that are widely used in food industries. Gelatin, an animal protein usually derived from mammalian or fish sources, is one of them. It has been used in most of the commercial and research applications as a wall material in various encapsulated foods [20]. However, recent encapsulation research has focused on finding suitable alternative to gelatin because gelatin is obtained from animal sources and is not accepted by certain group of consumers based on dietary preferences and religious beliefs [21] [22] [23]. As a result milk proteins viz. whey protein and casein and various proteins and polysaccharides of plant and microbial origin have been investigated for their applicability in food encapsulation [24] [25] [26] [27]. Various types of omega-3 oils [28] [29] [30], flavors [31], oleoresins [32] [33],vitamins [34], antioxidants [35], phenolic compounds [36], artificial sweeteners [14], probiotic microorganisms [37] [38], enzymes [39], acidulants [40] [41], leavening agents [42], colorants [43], and minerals [44] have successfully been encapsulated using various encapsulation methods and combination of shell matrices [7] [45] [46]. Reference [47] also encapsulated ethylene gas in a matrix of $\alpha$-cyclodextrin using inclusion complexation method so as to facilitate its handling and application in fruit ripening.

Stability of the encapsulated active is one of the most important aspects of encapsulation process. Various literature [48] [49] [50] [51] reported that stability of the active ingredient largely depends on the structure and functionality of shell matrix, the processing conditions and the core-shell interactions if any exist. The success of the encapsulation technology depends on correct approaches to understanding the sensitivity of the active ingredients to a variety of physical, chemical and environmental factors, which may cause either the loss of biological functionality, chemical degradation or a premature or incomplete release of the actives [50]. Therefore, study of the release behaviour of the active and in-vivo experimentation give better picture of the efficiency of the encapsulation process. Although there are several studies that focus on the microencapsulation process optimisation and increase in the stability of the core, there are limited studies that report the core release behaviour and kinetics, its digestibility and subsequent physiological utilisation. Recently, [52] studied the release patterns 
and digestibility of chia seed oil from the microcapsules prepared by using chia seed protein, chia seed gum and protein-gum complex coacervates as shell matrices. The authors have reported that complex coacervation based matrix not only enhances the stability of the PUFA-rich oil but also slows down its premature release in the oral or gastric phase, thus protecting the core from adverse effect and delivering it in the intestinal phase in intact form.

Spatial distribution of the core inside the microcapsule is also another important factor that influences the stability and release of the core; however, there is paucity of information in the literature on the topic. One of such studies [53] that investigated the distribution of chia seed oil inside the spray-dried microcapsule showed that nature and composition of microcapsule matrices had substantial influence on the core distribution, its stability and thus the release behaviour of the core from the matrix.

Microencapsulation technology has been gaining popularity in food and pharmaceutical industries in last 2 decades; however, it is becoming more and more popular in recent years. There are several book chapters, review articles and research papers published in this area that focus on various aspects of this emerging and innovative technology; however, there is still scarcity of articles that provide comprehensive review of various microencapsulation technologies and recent advances in that arena. Therefore, this article aims to fill that literature gap. We attempted to provide detailed information on currently available various microencapsulation techniques, shell materials used and future trends in microencapsulation and functional food sector. The performance measurement methods are also included. We believe that this review paper will be a useful resource for pharmaceutical scientists, food technologists and functional food manufacturers.

\section{Encapsulation Techniques}

Depending on the nature of the core and intended use of the finished products several encapsulation techniques have been investigated. Various methods of micro/nanoencapsulation have been described in various literatures with their application in food, pharmaceuticals, agriculture, textiles, paper and other allied industries [54] [55] [56] [57] [58]. These methods vary in their complexities. Coating of an active by a solution of shell material is the simplest method of encapsulation used in food industries. It involves pan, spray or fluidized bed coating followed by drying. Other methods involve the emulsification of a core material (e.g. oil or enzyme) with a solution of a wall material (usually a polysaccharide or a protein or their synergies) followed by drying process to obtain the encapsulated material in dry powdered form for convenient handling and storage [7].

The proper designing and functioning of encapsulation systems require a physicochemical understanding of the encapsulation mechanisms, possible interaction of the actives with the shell matrices, active stability and release behav- 
iour from the shell matrix. Incorporation of additional stabilizing agent can also play an important role in the success of the whole process of encapsulation [7] [59].

This section describes some of the commonly used encapsulation methods and recent development in their application in food research.

\subsection{Coating}

Coating of the granules, pellets or tablets with a solution of wall material by tumbling in a pan or similar equipment is the simple physicomechanical methods of encapsulation which is widely used in pharmaceutical and food industries [60]. Reference [61] reported the scale-up process for pan coating in pharmaceutical industries; however, application of this coating in food sector is not well advanced. Other methods used for coating food ingredients are spray [62] and fluidized bed coating [63] [64] [65] Fluidized bed coating, developed by D.E. Wurster in the 1950s is also named as Wurster process. Reference [64] reported three different types of fluidized bed coating techniques-top-spray, bottom-spray and hot-melt fluidised bed; top-spray coating is considered as the most feasible process, on technical and economic grounds, for industrial application. It is still a prefered method of encapsulation in various food industries owing to the lower cost of production and requirement of less sophisticated set up. In bottom spray coating, the liquid pulverizes concurrently with the air and the particles move towards the bottom of the coating chamber. The resultant collisions between droplets and particles increase the coating efficiency but lower the droplets drying. This bottom spray coating results in dense and homogeneous coating and minimal risk of agglomeration. The process has a greater drying capacity than other coating systems, due to a relatively high fluidizing air velocity. Hot melt fluidized bed coating is relatively newer method of coating used for encapsulating food ingredients using waxes and hydrogenated oils; however, it is less applicable for the material with melting point too close to the melting point of coating material [64]. Reactive layer coating has been reported for agricultural application [66]; however, it is rarely used in food industries. Reference [62] reported the simple scaling laws based on the geometry of the equipment and the flow of coating materials for both fluid bed and rotating drum coaters. Although this scale up was initialy for pharmaceutical application, they stated that this technology could be extended to food industries also. Similarly [67] developed a processing model for pan coating to facilitate the prediction of content uniformity of the active pharmaceutical ingredient; however, there is scarcity of information for the food ingredient encapsulation. Reference [68] reported a computational study using the discrete element method to investigate the effect of pan speed, fill level and the design of the spray pattern on the coating variability of tablets coated in a rotating pan. It was found that the axial mixing was the most critical parameter affecting the coating variability and the fill level [68]. 


\subsection{Spray Drying}

Spray drying is a highly effective and widely used encapsulation technique in food and pharmaceutical industries because of its comparative advantage over other methods of encapsulation. It is highly automated and cost-effective, and produces a good quality product. One of the most remarkable advantages of the spray drying is its capacity to process several kinds of materials to produce fairly dried product with pre-specified properties [69]. In this method, the active ingredient is well mixed in the encapsulating material forming an emulsion or a solution or a suspension. In general, the lipophilic core and hydrophilic shell materials are used to form an emulsion. The shell material is commonly a polysaccharide (e.g. gum or starch) or a protein (e.g. gelatin, milk protein or soy protein) or their synergies. Usually coarse emulsion is prepared by mixing the core and shell materials in required quantities. It is usually followed by single stage or two-stage homogenisation that yields a fine emulsion. This fine emulsion is atomized in a drying chamber at a pre-defined flow rate. Schematic diagram of the spray drying based encapsulation process is shown in Figure 2. When water from the emulsion is removed by application of thermal energy, it yields a coated dry active ingredient, more stable to moisture, oxygen, light and other environmental stressors [70]. Finally, the formation of matrix type micro capsules [71].

Spray drying technology provides high production rates at relatively low operating

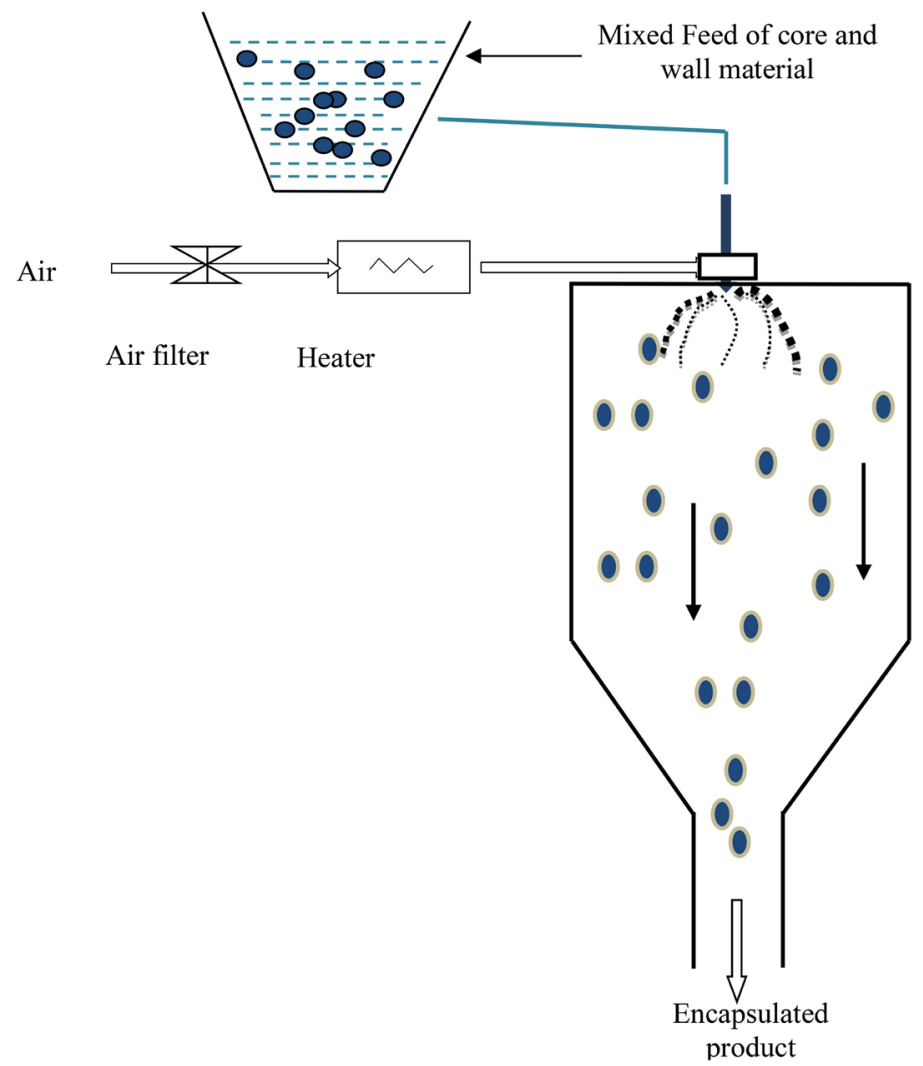

Figure 2. A schematic diagram of microencapsulation process by spray dryer. 
costs and the resulting product is stable and easily scalable [72]. Several unstable and sensitive products including polyunsaturated fats (PUFA), vitamins, enzymes and polyphenols can be encapsulated into inert matrices to make them stable and more effective. However, most probiotic strains do not survive well at high temperatures and dehydration during spray-drying process [70]. Loss of viability is principally caused by damage of cytoplasmic membranes [73] and associated proteins [74]. The introduction of thermoprotectants such as trehalose and prebiotics can improve the stability of biomaterials [69] and the viability of cells [70]. The addition of thermoprotectants has been used to help overcome microbial inactivation during drying and stabilization during storage.

\subsection{Fluidized Bed Coating/Air Suspension}

The process involves the preparation of coating solution, fluidization of core particles/tablets/granules followed by coating of core particles with coating solutions [64] [74]. The types of materials for fluidized bed coating are water-insoluble and water-soluble polymers, lipids and waxes. The particles/granules are sprayed with coating solution at a specific temperature (Figure 3). Application of high temperature is not required; hence, this method is efficient in saving energy and time. However, this method is commonly used for secondary coating of the primarily encapsulated products to enhance the stability. For example, corn starch coating was used as secondary coating on caseinate encapsulated fish oil [75].

\subsection{Spray Chilling and Spray Cooling}

Spray chilling is the process of solidifying an atomized liquid spray into particles. In these methods, mixture of core and wall is atomized into the cooled or chilled

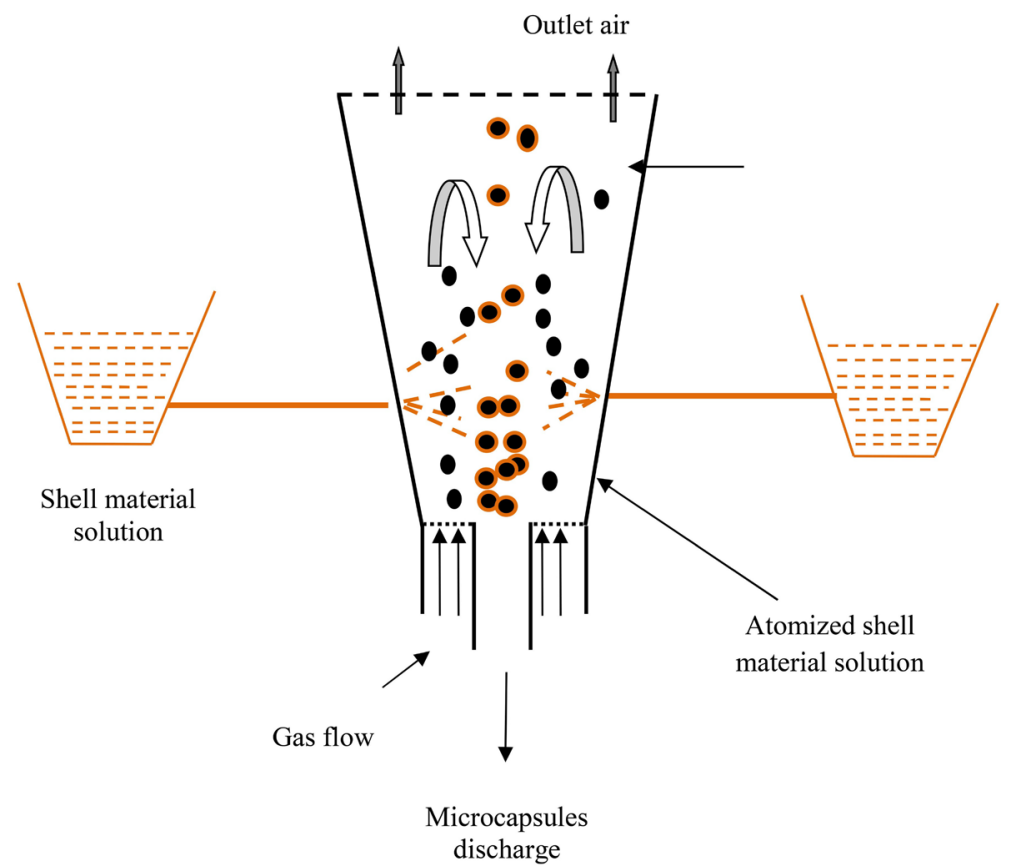

Figure 3. A schematic diagram of a fluidized bed coating. 
air, which causes the wall to solidify around the core [76]. Unlike spray-drying, spray-chilling or spray-cooling does not involve mass transfer (evaporation of water). Therefore, it is more energy efficient process. In spray-cooling, the coating material is typically some kinds of vegetable oils or its derivatives including fat and stearin with melting points of $45^{\circ} \mathrm{C}-72^{\circ} \mathrm{C}$, as well as hard mono- and diacylglycerols with melting points of $45^{\circ} \mathrm{C}-65^{\circ} \mathrm{C}$ [77]. In spray-chilling, the coating material is typically a fractionated or hydrogenated vegetable oil with a melting point in the range of $32^{\circ} \mathrm{C}-42^{\circ} \mathrm{C}$. In these processes, a melted lipid, above its melting point, is sprayed onto the core material and allowed to cool; instant solidification of the lipid takes place yielding almost perfect spherical and free-flowing microcapsule powders. Microcapsules prepared by spray-chilling and spray cooling are insoluble in water due to the lipid coating. Consequently, these techniques are utilized for encapsulating water-soluble core materials such as chemical fertilisers, pharmaceutical ingredients, water-soluble vitamins, enzymes, acidulants, and some flavors [78].

\subsection{Extrusion Coating}

Extrusion based encapsulation is a convenient method that can be applied to produce highly dense encapsulated products. It is a liquid co-extrusion process in which bioactive core and coating agent are pumped separately through a concentric orifice located on the outer circumference of a rotating cylinder (i.e. head). Core material flows through the centre of the tube; coating material flows through the other tube. Since the equipment is attached to a rotating shaft both the core and shell matrix are co-extruded through the concentric orifices as the head rotates. During this process, centrifugal force impels the rod outward, causing it to break into tiny particles. Due to the surface activity of the coating material, it quickly moves at the surface of the core until it completely surrounds the core material.

A number of innovative foods approved this coating system to encapsulate products such as flavourings, seasonings, vitamins, and many others. The most common extrusion techniques include resonance and jet-cutting technique as well as electrostatic droplet generation [70] [79] (Figure 4). In this method, low

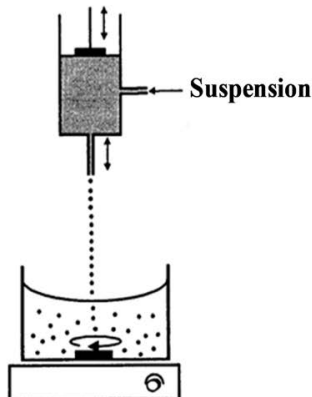

(a) Resonance method

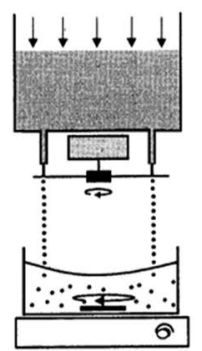

(b) Jet cutting method

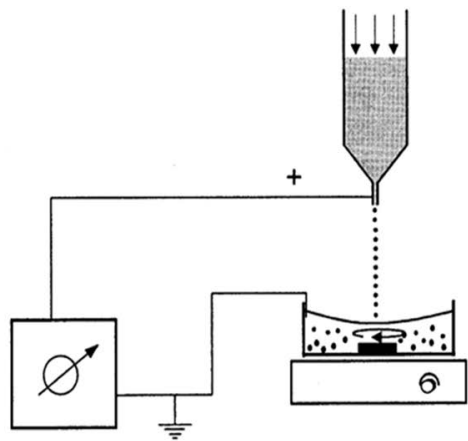

(c) Electrostatic droplet generation

Figure 4. Microsphere preparations by extrusion techniques. Adapted from [79]. 
molecular weight carbohydrates including reducing sugars and sugar alcohols are used as encapsulants. One of the advantages of extrusion based encapsulation is that resultant product is of larger particle sizes $(0.1-5.0 \mathrm{~mm})$ than that obtained from other methods of encapsulation. Bead diameter of up to $2.6 \mathrm{~mm}$ was reported in microencapsulation of B. longum in alginate [70].

Wall materials used in extrusion process of encapsulation include gelatin, sodium alginate, carrageenan, starches, cellulose derivatives, gum acacia, fats \& fatty acids, waxes, and polyethylene glycol [80] [81].

\subsection{Liposome Entrapment}

Liposome entrapment is a well-known method of microencapsulation since 1970s; however, it has gained popularity after 1990s. It is highly popular in drug delivery and nutraceutical industry in recent years. Liposomes consist of an aqueous phase that is completely surrounded by a phospholipid-based membrane [82]. These are formed in situ when phospholipids, such as lecithin, are dispersed in an aqueous phase. During spontaneous formation liposomes surround the core material which can be either aqueous or lipid-soluble. They have been used for delivery of vaccines, hormones, enzymes, vitamins and other sensitive neutraceuticals [83]. Usually, liposome based encapsulated products consist of one or more layers of lipids that surround unstable core. The resultant product is highly stable and of superior quality. Permeability, stability, surface activity, and affinity of the core and resultant product can be varied through variations in the size and lipid composition. They can range from $25 \mathrm{~nm}$ to several microns in diameter. Among various types of liposome that are used in encapsulation of food ingredients, large unilamellar vesicles are considered as the most appropriate liposomes due to their high encapsulation efficiency, simple production methods, and enhanced storage stability. It is also important to note that liposome based microencapsulation technology impart enhanced stability to water-soluble material in high water activity application. A process has been developed to stabilize vitamin $\mathrm{C}$ in the aqueous inner core of liposomes [84]. Encapsulation of vitamin $\mathrm{C}$ gave significant improvements in shelf life (from a few days to up to 2 months), especially in the presence of common food components that would normally speed up decomposition, such as copper ions, ascorbate oxidase, and lysine. Liposomes can also be used to deliver the encapsulated ingredient at a specific and well-defined temperature: the liposome bilayer is instantly broken down at the transition temperature of the phospholipids, typically around $50^{\circ} \mathrm{C}$, at which temperature the content is immediately released [78]. In a different study [85], it has been shown that liposome-entrapped nisin retained higher activity against Listeria innocua and had improved stability in cheese production, proving a powerful tool to inhibit the growth of Listeria.

Other microencapsulation techniques such as spray-drying, extrusion coating, and fluidized beds impart great stability to food ingredients in the dry state but release their content readily when the encapsulated product is exposed to high 
water activity environment. Targeted delivery of their content in desired site and specified conditions is an advantage of liposome entrapment [86]. The main issue with this method is associated with the scale up of the microencapsulation process to a commercial scale [78]. Combination of microfluidization technique with liposome entrapment process has been shown to be an effective, cost-effective, and solvent-free continuous method for the production of liposome entrapped bioactives, neutraceuticals and pharmaceutical ingredients with high encapsulation efficiency. The method can process a few hundred litres per hour of aqueous liposomes on a continuous basis [87] [88].

\subsection{Coacervation}

Coacervation is a partial desolvation of a homogeneous polymer solution into a polymer-rich phase (coacervate) and the poor polymer phase (equilibrium phase) [3]. The term originated from the Latin "acervus" meaning "heap". This was the first reported encapsulation process used for the industrial production of microencapsulated products. Coacervation is mainly divided into two categories: simple coacervation and complex coacervation. The mechanism of microcapsule formation for both processes is identical, except for the way in which the phase separation is carried out. In simple coacervation a desolvation agent is added for phase separation, whereas the complex coacervation involves interaction between two oppositely charged polymers. Basic steps in complex coacervation are: 1) preparation of solution of two polymers; 2) mixing of lipophilic core with a polymer solution to form emulsion; 3) mixing of another polymer solution; 4) change of $\mathrm{pH}$ or temperature to induce formation of two immiscible phases; 5) deposition of the coacervates around the core; and 6) rigidization of the coating by cross-linking or application of heat (Figure 5). This method is capable of producing particles with smaller sizes that ranges from 1 to $100 \mu \mathrm{m}$. It also gives unusually higher payload (upto $90 \%$ for single core and $60 \%$ for multicore encapsulation. In complex coacervation, a protein and a carbohydrate (gum) are usually chosen as the shell materials. Protein is a positively charged polymer, whereas gum is negatively charged. Various biopolymers have been investigated for complex coacervation based encapsulation process. Gelatin and gum arabic are the most widely used polymer pairs; however, in recent years, gelatin has

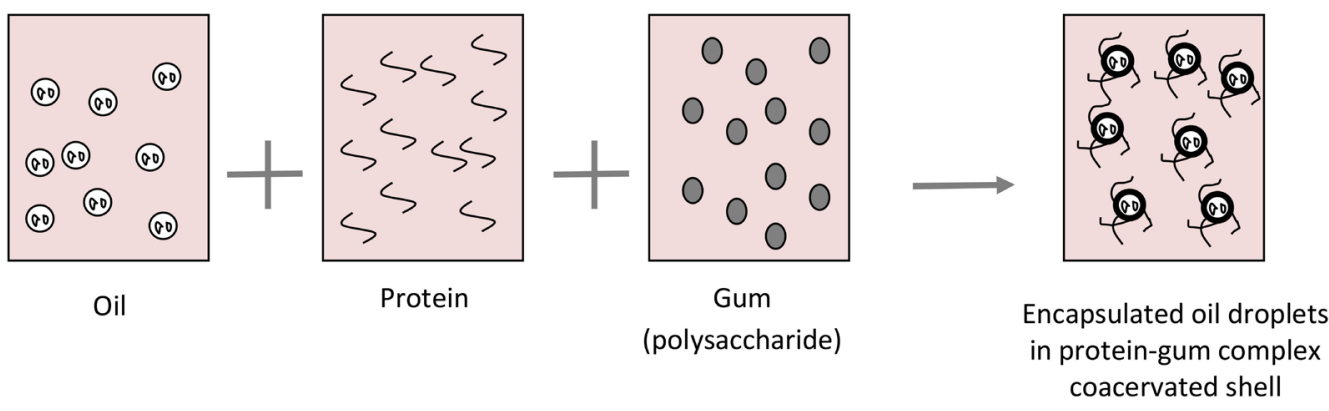

Figure 5. Flow diagram of the complex coacervation process; coating of core material (oil) by forming continuous shell around the core particles. 
been replaced with other proteins such as whey protein isolate, lactoferrin and bovine serum albumin [89].

Major disadvantage of complex coacervation based microencapsulation technology is that the coacervates are stable within a very narrow range of $\mathrm{pH}$ and ionic strength [53] [90] [91]. This limits the range of polymers that can be used as shell material in complex coacervation process. Another disadvantage is concentration of solute that can be used to form complex coacervates in solution form. The above discussion concludes that the complex coacervation method has huge application in food and pharmaceutical industry if associated bottlenecks are removed.

\subsection{Inclusion Complexation}

Inclusion complexation is another method of achieving encapsulation. This technique takes place at a molecular level where $\beta$-cyclodextrin is typically used as the encapsulating matrix. The external part of the cyclodextrin molecule is hydrophilic, whereas the internal part is hydrophobic. The bioactive cores, which are apolar, can be entrapped into the apolar internal cavity through a hydrophobic interaction [92]. $\beta$-Cyclodextrin molecules form inclusion complexes with compounds that can fit dimensionally into their central cavity (approx. 0.65 $\mathrm{nm}$ ) [93]. These complexes are formed in a reaction that takes place only in the presence of water. Molecules that are less polar than water (e.g flavor substances) and have suitable molecular dimensions to fit inside the cyclodextrin interior can be incorporated into the complex.

Based on the quantity of water used, there are three ways to produce $\beta$-cyclodextrin based encapsulated products. In the first method, $\beta$-cyclodextrin is dissolved in water to form an aqueous solution, and the flavors are added to form an inclusion complex in crystalline form. The crystal obtained is then recovered and dried to obtain the highly stable product. In the second method, $\beta$-cyclodextrin is dissolved in a lesser amount of water than in the first method to form a concentrated suspension, and the flavors are mixed to form an inclusion complex in crystalline form. The complex then must be recovered and dried to obtain free-flowing particles. In the third method, $\beta$-cyclodextrin is dissolved in a much lower quantity of water to form a paste, and the core materials are mixed thoroughly to form an inclusion complex. This method is superior to the former two because it does not require further separation and drying [92]. Among all existing microencapsulation methods, molecular inclusion of flavor volatiles in $\beta$-cyclodextrin molecules is the most effective for protecting the aromas. Encapsulating flavors in this way can provide better protection from volatilization during extrusion. However, the use of $\beta$-cyclodextrin for food application is very limited, possibly due to regulatory restriction in a number of countries [94].

\subsection{Ionotropic Gelation}

Ionotropic gelation involves interaction of an ionic polymer with oppositely 
charged ion that leads to complexation and cross-linking bewteen the two. The resultant product is also called a gelisphere. These gelispheres are crosslinked and spherical hydrophilic polymeric particles that can undergo extensive swelling in simulated biological fluids. This method is widely used encapsulation of neutraceutical and pharmaceutical products. In a study [95], tea catechins have successfully been encapsulated in chitosan-tripolyphosphate (CS-TPP) complex leading to the formation of nanoparticles using a simple ionotropic gelation method. In-vitro release study showed that the bioactive core (catechins) was released over more than 12 hours. Similarly [96] encapsulated selected micronutrients (ferrous fumarate, ascorbic acid, and $\beta$-carotene) using ionotropic gelation of alginate in native and functionalized form and evaluated their stability at two levels of temperature $\left(23^{\circ} \mathrm{C}\right.$ and $\left.45^{\circ} \mathrm{C}\right)$ and relative humidity (56\% and $\left.100 \%\right)$ for 6 months. Simulated gastro-intestinal study showed that beads were resistant to enzymatic and acidic attacks during stomach transit. The authors have concluded that simple ionotropic gelation can be used to yield highly stable encapsulated products that are resistant to heat, moisture and acid. It was also concluded that elongated shelf-life and sustained and targeted release of the actives can be achieved by judicious modification of biopolymer properties.

Although section 2 of this review article lists and describes various methods of encapsulation applied in food, nutraceutical and pharmaceutical industries, there are few other methods that have been in use for several years. Polymer-polymer incompatibility [97], Interfacial polymerization [97] [98], Vibrating Technology [57], Compression coating [99] and Interfacial solvent exchange [100] are some of them.

\section{Shell Materials Used for Food Ingredients Encapsulation}

A large number of substances are used to encapsulate solid or liquid food ingredients. The choice of encapsulating materials depends on the types, origins, and properties of these food ingredients. Among various shell materials only a limited number have been certified for food applications as "generally recognized as safe" (GRAS) materials. In general, these encapsulating agents are biopolymeric substances such as proteins, gums, lipids or their derivatives. A summary of these shell materials is provided in Table 1 [101] and the ensuing section provides more detailed information about these shell materials.

\subsection{Carbohydrates}

Starch and starch derivatives (e.g. maltodextrin), cellulose derivatives (e.g. carboxymethyl cellulose), gums (e.g. gum Arabic, guar gum and chia seed gum) and $\beta$-cyclodextrin are the commonly used carbohydrate based wall materials. Due to abundant availability, bland flavour, excellent core protection ability, these wall materials are used to encapsulate diverse food materials such as oxygen sensitive and PUFA-rich oil, vitamins, proteins \& bioactive peptides, enzymes and flavour [102] [103] [104]. Modified starches are produced by inducing side chains 
Table 1. Commonly used shell materials for microencapsulation in the food industry [101].

\begin{tabular}{|c|c|c|c|}
\hline Origin & Carbohydrate Polymers & Proteins & Lipids \\
\hline \multirow[t]{12}{*}{ Plant } & Starch and its derivatives & Gluten (corn) & Fatty Acids/Alcohols \\
\hline & Cellulose and its derivatives & $\begin{array}{l}\text { Isolates (pea, soy, } \\
\text { chia seed, wheat) }\end{array}$ & Glycerides \\
\hline & Plant Exudates & & Waxes \\
\hline & - Gum Arabic & & Phospholipids \\
\hline & - Gum Karaya & & \\
\hline & - Flax seed gum & & \\
\hline & - Chia seed gum & & \\
\hline & - Locust bean gum & & \\
\hline & Plant Extracts & & \\
\hline & - Galactomannans & & \\
\hline & - Soluble Soybean & & \\
\hline & Polysaccharides & & \\
\hline \multirow[t]{2}{*}{ Marine } & Carrageenan & & \\
\hline & Alginate & & \\
\hline \multirow[t]{4}{*}{ Microbial/Animal } & Xanthan & Caseins & Fatty Acids/Alcohols \\
\hline & Gellan & Whey Proteins & Glycerides \\
\hline & Dextran & Gelatin & Waxes \\
\hline & Chitosan & & Phospholipids (Shellac) \\
\hline
\end{tabular}

of lipophilic succinic acid to increase the emulsifying ability of starch. Modified starches are found to show better protection than native and waxy starch [105] and offer exciting emulsion stability [106].

Gum acacia (Arabic) has been proven as the most effective wall material in encapsulation of volatile materials such as flavours in spray drying process [107] [108] [109]. However, higher cost and limited availability of gum Arabic in comparison to other carbohydrate-based shell materials have restricted its usage as sole wall material for encapsulation of food ingredients. Therefore, it is blended with other wall materials such as maltodextrin and mesquite gum in order to reduce the cost of encapsulating oils and flavours [110] [111] [112].

Other carbohydrate-based wall materials such as $\beta$-cyclodextrins, alginates and chitosan are comparatively new and under study for diverse use in food sector [113] [114] [115] [116]. Seed gums/mucilages are currently highly explored carbohydrate-based encapsulating materials. Chia seed gum and flax seed gum have been used to form complex coacervate with chia seed protein and flax seed protein respectively to encapsulate PUFA-rich oils [117] [118]. One of the major advantages of using plant gums as encapsulants is their ability to resist gastro-intestinal digestion so that they also function as a source of soluble fibre 
and a prebiotic for gut microbiome. In addition, protein free starch and gums are also suitable to produce hypoallergenic products that are targeted for people with protein allergy.

\subsection{Proteins}

Superior physicochemical and functional properties including emulsifying capacity, gel forming ability and film formation capability make protein excellent encapsulating materials which find huge applications in food industries [119] [120]. Gelatin is the widely used shell matrix used to manufacture highly stable soft gels of omega-3, vitamin D and fish oil. Milk proteins (e.g. whey protein isolate and sodium caseinate) and other plant proteins (e.g. soy proteins, pea proteins) have been used as wall materials for several years. Whey protein has been reported as fantastic wall materials for encapsulating PUFA-rich oils and sensitive flavours. This protein possesses superior encapsulation efficiency (up to 89.6\%) over other proteins such as soy protein (up to 75.9\%) [121] [122]. The authors found that resultant microcapsules recovered by spray drying remain stable over 60 days at high water activity $\left(a_{w}=0.74-0.90\right)$ [122].

One of the major limitations of using protein as encapsulants is their allergenicity to some individuals. Soy proteins, wheat protein (e.g. gluten) and peanut proteins are reported to be highly allergenic to a number of individuals. This not only limits their application but also warrants manufacturer declaration on the label for their presence in the designed foods. In addition, proteins are sensitive to structural changes and their effectiveness as wall materials is greatly dependent such as $\mathrm{pH}$, ionic strength and temperature of the emulsions or solution [123] [124]. However, blending these proteins with other materials, particularly carbohydrate-based biopolymers, such as maltodextrin, corn syrup solids and lactose has been reported to be an effective method to minimise environmental effect on their functionality as encapsulants [125] [126].

\subsection{Lipids}

Lipids are hydrophobic materials and are insoluble in water. Therefore, they are widely used to encapsulate hydrophilic substances. Various types of lipids including glycerides, fatty acids, waxes and phospholipids have been explored for their ability to encapsulate food actives [101]. Although lipid based encapsulation technology is relatively young and emerging field, it is becoming highly popular as a means of delivering bioactive food, pharmaceutical and nutraceutical ingredients. Four common types of lipid based delivery systems are nanoemulsions, nanoliposomes, solid lipid nanoparticles and nanostructure lipid carriers [127].

\section{Measurement of Effectiveness of Microencapsulation Technique}

As mentioned previously, one of the important functions of encapsulating food 
bioactive is to protect it from the adverse environmental conditions including oxygen, moisture, light, heat and $\mathrm{pH}$ conditions. Ideally, encapsulated bioactive is isolated from the environmental stressors. Thus, it becomes stable for longer period of time. Encapsulated active is fully protected from its unwanted decomposition and immature release which enhance its bioavailability in the body. An encapsulation process is regarded successful only when the objective is achieved in more efficient and cost-effective way. Therefore, measurement of the effectiveness of encapsulation process is essential to assess the success of the developed technology. Although the effectiveness of the encapsulation process is influenced by several factors, the following parameters are commonly used to assess its performance.

\subsection{Encapsulation Efficiency}

Encapsulation efficiency $(E E)$ is the most important parameter to assess the effectiveness of the encapsulation process. $E E$ determines the percentage of bioactive substance entrapped inside the inert core during encapsulation process. This can be defined as the ratio of the mass of the core material which is fully entrapped inside the wall material to the mass of the core material used in the formulation. In simple term, if almost all the bioactive is completely entrapped inside the shell matrix and enhanced the stability of the active, the encapsulation process results in the highest encapsulation efficiency. In another words, the technology is successful in providing high degree of protection to the bioactive core. In the case of PUFA-rich oil encapsulation, entrapment of almost all the oil inside the shell matrix is desirable which leaves negligible quantity of oil on the surface of the shell matrix. The oil that is not fully entrapped by the shell matrix remains on the surface of the shell. This is known as surface fat or free fat. The surface oil undergoes rapid oxidative degradation as soon as the capsules are exposed to an ambient atmosphere. Therefore, high surface oil tends to correlate with off-flavour of microcapsules and reduced consumer acceptance of the resultant product. Ideally for safe storage of microcapsules the surface oil content should be below $0.1 \%(\mathrm{w} / \mathrm{w})$, although many emulsion products contain significantly higher quantity of surface oil [128]. When oil is encapsulated, the $E E$ can be calculated by using Equation (1).

$$
E E=\frac{W_{t}-W_{s}}{W_{t}}
$$

where, $E E$ is encapsulation efficiency, $W_{t}$ is mass of total oil and $W_{s}$ is the mass of surface oil on the microcapsule. Since $E E$ is one of the important parameters to measure the effectiveness of the encapsulation process, it is generally measured in almost all the microencapsulation researches. Since higher $E E$ is associated with better stability and longer shelf-life of the core, it is always desirable to increase the $E E$ by choosing the best possible combination of core-wall ratio, homogenisation process, drying methods and other relevant process variables. The calculation of $E E$ of some important food materials such as flaxseed oil, 
omega-3 fatty acids and probiotic bacteria can be found at relevant literatures [38] [129] [130] .

\subsection{Release Kinetics}

Pattern and kinetics of release of the core material from the capsule is another main parameter to be used to assess the effectiveness of the encapsulation process. Various methods are used to measure release of bioactive ingredients from the capsules. Release can be site-specific, stage-specific or triggered by changes in $\mathrm{pH}$, temperature, irradiation or osmotic shock. In the food industry the most common method is the solvent-activated release. The addition of water to dry beverages or cake mixes is an example. The release of encapsulated materials depends on several factors; 1 ) diffusivity of the bioactive core through the shell matrix 2) properties of shell matrix such as thickness and integrity 3) type and geometry of the particle 4) transform affinity from the matrix to environment/solvent and 5) degradation/dissolution of the matrix materials [7] [131]. In most food applications, the core material is released by simple diffusion or dissolution of the shell matrix due to mechanical force or enzymatic activity.

\subsection{Particle Size}

Particle size and their homogeneity is another parameter that determines the effectiveness of chosen encapsulation technology. The distribution of the particle size should be as narrow as possible in order to maintain product consistency. The size of the microcapsules can be measured using techniques such as laser scattering (e.g. mastersizer) or particle size imaging using microscopy. High resolution imaging using electron microscopy or confocal laser scanning microscope (CSLM) is useful for studying the detailed morphology of microcapsules. CSLM can be combined with staining techniques to gain better insights into the characteristics and distribution of the hydrophobic core and the hydrophilic shell. The size of microcapsules for food applications should be below $100 \mu \mathrm{m}$ to avoid impacting the mouth feel (i.e. grittiness) of the food product [128].

\subsection{Stability}

Stability of microcapsules is very important measure to assess the effectiveness of the encapsulation process and quality of resultant product. For example, the primary purpose of microencapsulation of omega-3 rich oils is to protect the sensitive omega- 3 fatty acids against oxidation by providing an oxygen barrier in the form of inert shell matrix. It is understood that different wall materials offer different degree of oxidative stability to the core, primarily depending upon the ability of the shell to inhibit oxygen transfer through it. In general, the oxidative stability of encapsulated oil is measured by storing the microcapsules under a set temperature and relative humidity for a defined period followed by measuring the resultant primary and secondary oxidation products; however, accelerated methods of measuring the oxidative stability are becoming increasingly popular. 
These accelerated methods include Rancimat ${ }^{\circledR}$, Oxypress etc. In principle, the unsaturated fatty acids, especially, omega- 3 and omega- 6 are the most susceptible components to oxidative degradation.

\subsection{Payload}

Payload is another measure of effectiveness of an encapsulation process. This is the percentage of the oil or active ingredient per gram of the powder. When an encapsulation process achieves a higher payload, the production of the microcapsules becomes more economical and the process is considered more effective. High payload means that the resultant product contains higher quantity of active ingredients and thus lesser quantity of resultant product is sufficient to deliver the same quantity of bioactive per serving of the food. Payload is calculated by taking the ratio of mass of active ingredient to total mass of the resultant encapsulated product. The mass of encapsulated oil can be determined gravimetrically by quantitative extraction of oil from a known quantity of microcapsules, followed by weighing the extracted oil. This is a destructive method and is time consuming and expensive for quality control purposes. A Fourier Transform Infrared (FTIR) spectroscopy-based non-destructive method has been recently developed to determine payload [132].

Equation (2) is used to calculate payload.

$$
P L=\frac{W_{t}}{W_{m}} \times 100
$$

where, $P L$ is the payload, $W_{t}$ is the mass of the total active encapsulated and $W_{m}$ is the total mass of the resultant product (i.e. mass of both active and shell).

\subsection{Encapsulation Yield}

Encapsulation yield $(E Y)$ is another factor to be considered during an encapsulation process. $E Y$ also measures the effectiveness of encapsulation. Equation (3) is used to calculate $E Y$.

$$
E Y=\frac{W_{t}}{W_{i}} \times 100
$$

where, $E Y$ is encapsulation yield, $W_{t}$ is mass of the total encapsulated active ingredient and $W_{i}$ is the mass of the active introduced.

\section{Future Perspective}

Although encapsulation technology has been used in various industries for more than six decades, there have been several advancements in both the science as well as the practical application of this technique since its first commercial application in 1950. It is being increasingly popular in pharmaceutical, nutraceutical and functional food industries as a highly effective method that performs various functions; the major being prolonging the shelf-life of the active, masking the undesirable flavour, colour and taste and controlling the release of bioac- 
tive. Encapsulation methods for new bioactives are being explored and research advancement is underway to improve the process and product characteristics. Innovative food-grade encapsulants are being explored to reduce the production costs and meet other technical specifications and consumer expectations.

With the escalating demand of functional foods including omega-3s, probiotics, vitamins and phytochemicals, these functional ingredients are being incorporated into wide range of products such as breads, milk, fruit juices, tortillas, chocolate, yoghurt drinks, spreads, peanut butter, eggs and meat. Accordingly, various methods of microencapsulation of different bioactives have been developed. At present, spray drying-based microencapsulation method is being widely used in various industrial applications; however, more advanced methods including complex coacervation are gaining increased attention in recent years. Complex coacervation technology has been reported to receive a high product yield and the resultant product possesses prolonged stability even at a very high payload (up to 99\%). In addition, it yields products with lowest unit product cost [133]. The biggest disadvantage of this technology is limited availability of shell materials. So far, gelatin is the only protein which is successfully used in commercial scale.

A number of studied have reported that the plant proteins are capable of forming coacervates in the presence of polysaccharides [117] [128]. This corroborates that plant proteins can be used instead of animal proteins in complex coacervation process. Reference [134] used $\alpha$-gliadin (cereals) and pea globulin (legume) in complex coacervation process. These authors found that both these proteins form excellent complex coacervates with the gum Arabic. However, the application of $\alpha$-gliadin in the coacervation process will not achieve widespread acceptance as this protein is associated with some kind of allergenicity in some individuals [134]. So, there is a need to test other plant polysaccharides for their potential as encapsulating and delivery vehicles of active ingredients. There are certain characteristics which are looked for before using a biopolymer as an encapsulant. Among them are emulsifying and interfacial properties, film forming abilities, solubility and gel-forming properties.

Emulsifying properties of flaxseed protein, chia seed protein and lentil protein have been evaluated in recent years [117] [118] [135]. It was found that emulsions stabilized by flax protein concentrate (FPC) at neutral $\mathrm{pH}$ and in the absence of salt had a smaller droplet size and higher surface charge which makes them good candidates to be used in coacervation process. FPC-stabilized emulsions were more stable against the effect of salt concentration. The FPC can be effective stabilizing emulsions where droplet size and zeta-potential are major factors influencing the emulsion stability. Flaxseed gum is also found to possess good potential in stabilizing the protein-based emulsions [136]. Encapsulating unstable and bioactive core materials with a protein-gum complex shell matrix isolated from the same plant source is a very recent idea of microencapsulation. Reference [118] successfully encapsulated flaxseed oil (core) by novel matrix of 
flaxseed protein-flaxseed gum complex coacervate. Similarly, [117] successfully encapsulated chia seed oil using chia seed protein-gum complex coacervate shell matrix. The authors have compared the effectiveness of protein only and gum only shell matrix with the complex coacervate shell matrix and concluded that complex coacervation based shell matrix is more effective over the other two. However, this laboratory experiments need further study for their effectiveness and reproducibility in pilot plant or commercial trials.

\section{Conclusion}

Although there are various reasons of microencapsulation, many bioactive ingredients are encapsulated to enhance their longevity and functionality. Several bioactive ingredients are encapsulated to prevent their degradation from environmental stressors and control their release in the gastrointestinal tract. For example, baking yeast and dough conditioners are encapsulated to increase their performance or to overcome other processing challenges. It has been reported that uncoated chemical leaveners release carbon dioxide prematurely. This is even more prominent in warmer environments. In addition, ingredient degradation or flavour loss during the baking process can occur in systems where uncoated ingredients are used. PUFAs-rich oils are encapsulated to prevent or minimise their oxidation. Bioactive peptides are encapsulated to control their release in targeted site. Therefore, encapsulation method is dependent on the nature of core material and intended use of the final product. As a consequence, various methods of encapsulation are developed.

\section{Conflicts of Interest}

The authors declare no conflicts of interest regarding the publication of this paper.

\section{References}

[1] Gibbs, B.F., Kermasha, S., Alli, I. and Mulligan, C.N. (1999) Encapsulation in the Food Industry: A Review. International Journal of Food Sciences and Nutrition, 50, 213-224. https://doi.org/10.1080/096374899101256

[2] Zuidam, N.J. and Nedovic, V.A., Eds. (2010) Encapsulation Technologies for Active Food Ingredients and Food Processing. Springer Science + Business Media, LLC, New York. https://doi.org/10.1007/978-1-4419-1008-0

[3] Jyothi, N.V.N., Prasanna, P.M., Sakarkar, S.N., Prabha, K.S., Ramaiah, P.S. and Srawan, G.Y. (2010) Microencapsulation Techniques, Factors Influencing Encapsulation Efficiency. Journal of Microencapsulation, 27, 187-197. https://doi.org/10.3109/02652040903131301

[4] Barros, D.M., Machado, E.C.L., Moura, D.F., Oliveira, M.H.M., Rocha, T.A., Ferreira, S.A.O., Fonte, R.A.B. and Bezerra, R.S. (2018) Potential Application of Microencapsulation in the Food Industry. International Journal of Advanced Research, 6, 956-976. https://doi.org/10.21474/IJAR01/8222

[5] Bisceglie, V. (1993) About Antineoplastic Immunity; Heterologous Implantation of Tumors in Chicken Embryos. Journal of Cancer Research, 40, 122-140. 
[6] Wang, J.Z., Ding, Z.Q., Zhang, F. and Ye, W.B. (2017) Recent Development in Cell Encapsulations and Their Therapeutic Applications. Materials Science and Engineering, 77, 1247-1260. https://doi.org/10.1016/j.msec.2017.04.103

[7] Madene, A., Jacquot, M., Scher, J. and Desobry, S. (2006) Flavour Encapsulation and Controlled Release-A Review. International Journal of Food Science \& Technology, 41, 1-21. https://doi.org/10.1111/j.1365-2621.2005.00980.x

[8] Weinbreck, F., Minor, M. and De Kruif, C. (2004) Microencapsulation of Oils Using Whey Protein/Gum Arabic Coacervates. Journal of Microencapsulation, 21, 667-679. https://doi.org/10.1080/02652040400008499

[9] Connick, J. and William, J. (1983) Controlled Release of Bioactive Materials Using Alginate Gel Beads. US Patents No. 4401456.

[10] De Vos, P., Faas, M.M., Spasojevic, M. and Sikkema, J. (2010) Encapsulation for Preservation of Functionality and Targeted Delivery of Bioactive Food Components. International Dairy Journal, 20, 292-302. https://doi.org/10.1016/j.idairyj.2009.11.008

[11] Mogol, B.A., Gokmen, V. and Shimoni, E. (2013) Nano-Encapsulation Improves Thermal Stability of Bioactive Compounds Omega Fatty Acids and Silymarin in Bread. Agro Food Industry Hi-Tech, 24, 62-65.

[12] Fu, N., You, Y., Quek, S.Y., Wu, W.D. and Chen, X.D. (2020) Interplaying Effects of Wall and Core Materials on the Property and Functionality of Microparticles for Co-Encapsulation of Vitamin E with Coenzyme $\mathrm{Q}_{10}$. Food and Bioprocess Technology, 13, 705-721. https://doi.org/10.1007/s11947-020-02431-y

[13] Cárdenas-Bailón, F., Osorio-Revilla, G. and Gallardo-Velázquez, T. (2012) Microencapsulation Techniques to Develop Formulations of Insulin for Oral Delivery: A Review. Journal of Microencapsulation, 30, 409-424. https://doi.org/10.3109/02652048.2012.742159

[14] Rocha-Selmi, G.A., Bozza, F.T., Thomazini, M., Bolini, H.M.A. and Fávaro-Trindade, C.S. (2013) Microencapsulation of Aspartame by Double Emulsion Followed by Complex Coacervation to Provide Protection and Prolong Sweetness. Food Chemistry, 139, 72-78. https://doi.org/10.1016/j.foodchem.2013.01.114

[15] Trojer, M.A., Nordstierna, L., Nordin, M., Nydén, M. and Holmberg, K. (2013) Encapsulation of Actives for Sustained Release. Physical Chemistry Chemical Physics, 15, 17727-17741. https://doi.org/10.1039/c3cp52686k

[16] Eratte, D., Dowling, K., Barrow, C.J. and Adhikari, B. (2018) Recent Advances in the Microencapsulation of Omega-3 Oil and Probiotic Bacteria through Complex Coacervation: A Review. Trends in Food Science \& Technology, 71, 121-131. https://doi.org/10.1016/j.tifs.2017.10.014

[17] Dziubla, T.D., Shuvaev, V.V., Hong, N., Hawkins, B.J., Madesh, M., Takano, H. and Muzykantov, V.R. (2008) Endothelial Targeting of Semi-Permeable Polymer Nanocarriers for Enzyme Therapies. Biomaterials, 29, 215-227. https://doi.org/10.1016/j.biomaterials.2007.09.023

[18] Weinbreck, F., Bodnár, I. and Marco, M.L. (2010) Can Encapsulation Lengthen the Shelf-Life of Probiotic Bacteria in Dry Products? International Journal of Food Microbiology, 136, 364-367. https://doi.org/10.1016/j.ijfoodmicro.2009.11.004

[19] Dziubla, T.D., Karim, A. and Muzykantov, V.R. (2005) Polymer Nanocarriers Protecting Active Enzyme Cargo against Proteolysis. Journal of Controlled Release, 102, 427-439. https://doi.org/10.1016/j.jconrel.2004.10.017

[20] Karim, A.A. and Bhat, R. (2009) Fish Gelatin: Properties, Challenges, and Prospects as an Alternative to Mammalian Gelatins. Food Hydrocolloids, 23, 563-576. 
https://doi.org/10.1016/j.foodhyd.2008.07.002

[21] Karim, A.A. and Bhat, R. (2008) Gelatin Alternatives for the Food Industry: Recent Developments, Challenges and Prospects. Trends in Food Science \& Technology, 19, 644-656. https://doi.org/10.1016/j.tifs.2008.08.001

[22] Morrison, N., Clark, R., Chen, Y., Talashek, T. and Sworn, G. (1999) Gelatin Alternatives for the Food Industry. In: Nishinari, K., Ed., Physical Chemistry and Industrial Application of Gellan Gum, Springer, Berlin, 127-131. https://doi.org/10.1007/3-540-48349-7_19

[23] Ogura, T., Furuya, Y. and Matsuura, S. (1998) HPMC Capsules: An Alternative to Gelatin. Pharmaceutical Technology Europe, 10, 32-42.

[24] De Kruif, C.G., Weinbreck, F. and de Vries, R. (2004) Complex Coacervation of Proteins and Anionic Polysaccharides. Current Opinion in Colloid \& Interface Science, 9, 340-349. https://doi.org/10.1016/j.cocis.2004.09.006

[25] Eraso, M.O. and Herrera, A. (2013) Use of Starches and Milk Proteins in Microencapsulation. International Journal of Vegetable Science, 20, 289-304. https://doi.org/10.1080/19315260.2013.803181

[26] Weinbreck, F., Nieuwenhuijse, H., Robijn, G.W. and de Kruif, C.G. (2004) Complexation of Whey Proteins with Carrageenan. Journal of Agricultural and Food Chemistry, 52, 3550-3555. https://doi.org/10.1021/jf034969t

[27] Hoyos-Leyva, J.D., Bello-Pérez, L.A., Alvarez-Ramirez, J. and Garcia, H.S. (2018) Microencapsulation Using Starch as Wall Material: A Review. Food Reviews International, 34, 148-161. https://doi.org/10.1080/87559129.2016.1261298

[28] Barrow, C.J., Wang, B., Adhikari, B. and Liu, H. (2013) Spray Drying and Encapsulation of Omega-3 Oils. In: Jacobsen, C., Nielsen, N.S., Horn, A.F. and Moltke Sørensen, A. (Eds.), Food Enrichment with Omega-3 Fatty Acids. A Volume in Woodhead Publishing Series in Food Science, Technology and Nutrition, Woodhead Publishing, Sawston, Cambridge, 194-225. https://doi.org/10.1533/9780857098863.2.194

[29] Timilsena, Y.P., Adhikari, R., Barrow, C.J. and Adhikari, B. (2016) Physicochemical and Functional Properties of Protein Isolate Produced from Australian Chia Seeds. Food Chemistry, 212, 648-656. https://doi.org/10.1016/j.foodchem.2016.06.017

[30] Wang, B., Adhikari, B. and Barrow, C.J. (2018) Highly Stable Spray Dried Tuna Oil Powders Encapsulated in Double Shells of Whey Protein Isolate-Agar Gum and Gellan Gum Complex Coacervates. Powder Technology, 358, 79-86. https://doi.org/10.1016/j.powtec.2018.07.084

[31] Xiao, Z.L., Wanlong, Z., Guangyong, Z.R. and Niu, Y. (2013) A Review of the Preparation and Application of Flavour and Essential Oils Microcapsules Based on Complex Coacervation Technology. Journal of the Science of Food and Agriculture, 94, 1482-1494. https://doi.org/10.1002/jsfa.6491

[32] Shaikh, J., Bhosale, R. and Singhal, R. (2006) Microencapsulation of Black Pepper Oleoresin. Food Chemistry, 94, 105-110. https://doi.org/10.1016/j.foodchem.2004.10.056

[33] Rascón, M.P., Beristain, C.I., García, H.S. and Salgado, M.A. (2011) Carotenoid Retention and Storage Stability of Spray-Dried Encapsulated Paprika Oleoresin Using Gum Arabic and Soy Protein Isolate as Wall Materials. LWT-Food Science and Technology, 44, 549-557. https://doi.org/10.1016/j.lwt.2010.08.021

[34] Gonnet, M., Lethuaut, L. and Boury, F. (2010) New Trends in Encapsulation of Liposoluble Vitamins. Journal of Controlled Release, 146, 276-290.

https://doi.org/10.1016/j.jconrel.2010.01.037 
[35] Deladino, L., Anbinder, P.S., Navarro, A.S. and Martino, M.N. (2008) Encapsulation of Natural Antioxidants Extracted from Ilex paraguariensis. Carbohydrate Polymers, 71, 126-134. https://doi.org/10.1016/j.carbpol.2007.05.030

[36] Munin, A. and Edwards-Lévy, F. (2011) Encapsulation of Natural Polyphenolic Compounds: A Review. Pharmaceutics, 3, 793-829. https://doi.org/10.3390/pharmaceutics3040793

[37] Cook, M.T., Tzortzis, G., Charalampopoulos, D. and Khutoryanskiy, W. (2012) Microencapsulation of Probiotics for Gastrointestinal Delivery. Journal of Controlled Release, 162, 56-67. https://doi.org/10.1016/j.jconrel.2012.06.003

[38] Eratte, D., McKnight, S., Gengenbach, T.R., Dowling, K., Barrow, C.J. and Adhikari, B.P. (2015) Co-Encapsulation and Characterisation of Omega-3 Fatty Acids and Probiotic Bacteria in Whey Protein Isolate-Gum Arabic Complex Coacervates. Journal of Functional Foods, 19, 882-892. https://doi.org/10.1016/j.jff.2015.01.037

[39] Jiang, H., Zhang, M., McKnight, S. and Adhikari, B. (2013) Microencapsulation of $\alpha$-Amylase by Carrying out Complex Coacervation and Drying in a Single Step Using a Novel Three-Fluid Nozzle Spray Drying. Drying Technology, 31, 1901-1910. https://doi.org/10.1080/07373937.2013.771365

[40] Boghani, N., Gebreselassie, P. and Vyakaranam, K. (2012) Encapsulated Acid, Method for the Preparation Thereof, and Chewing Gum Comprising Same. U.S. Patent Application No. 15/595,105.

[41] Mitchell, W.A. and Seidel, W.C. (1977) Dry Acidulents. US Patent No. 4,022,924.

[42] Merritt, C.G. (1981) Encapsulation of Materials. US Patents No. 4276312 A.

[43] Serris, G.S. and Biliaderis, C.G. (2001) Degradation Kinetics of Beetroot Pigment Encapsulated in Polymeric Matrices. Journal of the Science of Food and Agriculture, 81, 691-700. https://doi.org/10.1002/jsfa.864

[44] Van Lengerich, B.H. and Lakkis, J. (2002) Production of Oil Encapsulated Minerals and Vitamins in a Glassy Matrix. US Patent No. 6,436,453.

[45] Risch, S.J. (1995) Encapsulation: Overview of Uses and Techniques. In: Risch, S.J. and Reineccius, G., Eds., Encapsulation and Controlled Release of Food Ingredients, ACS Symposium Series, Vol. 590, ACS Publications, Washington DC, 2-7. https://doi.org/10.1021/bk-1995-0590.ch001

[46] Ozkan, G., Franco, P., Marco, I.D., Xiao, J. and Capanoglu, E. (2019) A Review of Microencapsulation Methods for Food Antioxidants: Principles, Advantages, Drawbacks and Applications. Food Chemistry, 272, 494-506. https://doi.org/10.1016/j.foodchem.2018.07.205

[47] Ho, B.T., Joyce, D.C. and Bhandari, B.R. (2011) Encapsulation of Ethylene Gas into $\alpha$-Cyclodextrin and Characterisation of the Inclusion Complexes. Food Chemistry, 127, 572-580. https://doi.org/10.1016/j.foodchem.2011.01.043

[48] Drusch, S. and Mannino, S. (2009) Patent-Based Review on Industrial Approaches for the Microencapsulation of Oils Rich in Polyunsaturated Fatty Acids. Trends in Food Science \& Technology, 20, 237-244. https://doi.org/10.1016/j.tifs.2009.03.007

[49] Lemetter, C., Meeuse, F. and Zuidam, N. (2009) Control of the Morphology and the Size of Complex Coacervate Microcapsules during Scale-Up. AIChE Journal, 55, 1487-1496. https://doi.org/10.1002/aic.11816

[50] Ubbink, J. and Krüger, J. (2006) Physical Approaches for the Delivery of Active Ingredients in Foods. Trends in Food Science \& Technology, 17, 244-254. https://doi.org/10.1016/j.tifs.2006.01.007

[51] Soni, N., Shah, N.N. and Singhal, R.S. (2019) Dodecenyl Succinylated Guar Gum 
Hydrolysate as a Wall Material for Microencapsulation: Synthesis, Characterization and Evaluation. Journal of Food Engineering, 242, 133-140. https://doi.org/10.1016/j.jfoodeng.2018.08.030

[52] Timilsena, Y.P., Adhikari, R., Barrow, C.J. and Adhikari, B. (2017) Digestion Behaviour of Chia Seed Oil Encapsulated in Chia Seed Protein-Gum Complex Coacervates. Food Hydrocolloids, 66, 71-81. https://doi.org/10.1016/j.foodhyd.2016.12.017

[53] Timilsena, Y.P., Vongsvivut, J., Tobin, M.J., Adhikari, R., Barrow, C. and Adhikari, B. (2019) Investigation of Oil Distribution in Spray-Dried Chia Seed Oil Microcapsules Using Synchrotron-FTIR Microspectroscopy. Food Chemistry, 275, 457-466. https://doi.org/10.1016/j.foodchem.2018.09.043

[54] Dubey, R., Shami, T.C. and Bhasker Rao, K.U. (2009) Microencapsulation Technology and Applications. Defence Science Journal, 59, 82-95.

[55] Mozafari, M.R., Khosravi-Darani, K., Borazan, G.G., Cui, J., Pardakhty, A. and Yurdugul, S. (2008) Encapsulation of Food Ingredients Using Nanoliposome Technology. International Journal of Food Properties, 11, 833-844. https://doi.org/10.1080/10942910701648115

[56] Okuro, P.K., de Matos Junior, F.E. and Favaro-Trindade, C.S. (2013) Technological Challenges for Spray Chilling Encapsulation of Functional Food Ingredients. Food Technology and Biotechnology, 51, 171-182. https://hrcak.srce.hr/104707

[57] Whelehan, M. and Marison, I.W. (2011) Microencapsulation Using Vibrating Technology. Journal of Microencapsulation, 28, 669-688. https://doi.org/10.3109/02652048.2011.586068

[58] Yonekura, L., Sun, H., Soukoulis, C. and Fisk, I. (2014) Microencapsulation of Lactobacillus acidophilus NCIMB 701748 in Matrices Containing Soluble Fibre by Spray Drying: Technological Characterization, Storage Stability and Survival after in Vitro Digestion. Journal of Functional Foods, 6, 205-214. https://doi.org/10.1016/j.jff.2013.10.008

[59] Augustin, M.A. and Hemar, Y. (2009) Nano- and Micro-Structured Assemblies for Encapsulation of Food Ingredients. Chemical Society Reviews, 38, 902-912. https://doi.org/10.1039/B801739P

[60] Vidhyalakshmi, R., Bhakyaraj, R. and Subhasree, R. (2009) Encapsulation "The Future of Probiotics"-A Review. Advances in Biological Research, 3, 96-103. http://www.idosi.org/abr/3(3-4)/8.pdf

[61] Pandey, P., Turton, R., Joshi, N., Hammerman, E. and Ergun, J. (2006) Scale-Up of a Pan-Coating Process. AAPS PharmSciTech, 7, E125-E132. https://doi.org/10.1208/pt0704102

[62] Turton, R. and Cheng, X.X. (2005) The Scale-Up of Spray Coating Processes for Granular Solids and Tablets. Powder Technology, 150, 78-85.

https://doi.org/10.1016/j.powtec.2004.11.021

[63] Baldwin, E.A., Hagenmaier, R. and Bai, J. (2011) Edible Coatings and Films to Improve Food Quality. CRC Press, Boca Raton, FL. https://doi.org/10.1201/b11082

[64] Dewettinck, K. and Huyghebaert, A. (1999) Fluidized Bed Coating in Food Technology. Trends in Food Science \& Technology, 10, 163-168. https://doi.org/10.1016/S0924-2244(99)00041-2

[65] Kitajima, M., Asaka-shi, O.-M., Yamaguchi, T., Ohhito-cho, M., Kondo, A. and Muroya, N. (1972) Encapsulation Method. US Patent No. 3,691,090.

[66] Shaviv, A. (2000) Advances in Controlled Release of Fertilizers. Advances in Agronomy, 71, 1-49. https://doi.org/10.1016/S0065-2113(01)71011-5 
[67] Chen, W., Chang, S.Y., Kiang, S., Marchut, A., Lyngberg, O., Wang, J. and Early, W. (2010) Modeling of Pan Coating Processes: Prediction of Tablet Content Uniformity and Determination of Critical Process Parameters. Journal of Pharmaceutical Sciences, 99, 3213-3225. https://doi.org/10.1002/jps.22044

[68] Dubey, A., Hsia, R., Saranteas, K., Brone, D., Misra, T. and Muzzio, F.J. (2011) Effect of Speed, Loading and Spray Pattern on Coating Variability in a Pan Coater. Chemical Engineering Science, 66, 5107-5115.

https://doi.org/10.1016/j.ces.2011.07.010

[69] Haque, M.A., Aldred, P., Chen, J. and Adhikari, B. (2015) Denaturation and Physical Characteristics of Spray Dried Whey Protein Isolate Powders Produced in the Presence and Absence of Lactose, Trehalose and Polysorbate-80. Drying Technology, 33, 1243-1254. https://doi.org/10.1080/07373937.2015.1023311

[70] Petrović, T., Nedović, V., Dimitrijević-Branković, S., Bugarski, B. and Lacroix, C. (2007) Protection of Probiotic Microorganisms by Microencapsulation. Chemical Industry and Chemical Engineering Quarterly, 13, 169-174. https://doi.org/10.2298/CICEQ0703169P

[71] Kailasapathy, K. (2002) Microencapsulation of Probiotic Bacteria: Technology and Potential Applications. Current Issues in Intestinal Microbiology, 3, 39-48. https://www.caister.com/ciim/v/v3/05.pdf

[72] Ortega-Rivas, E., Juliano, P. and Yan, H. (2005) Food Powders: Physical Properties, Processing, and Functionality. Springer, Berlin.

[73] Teixeira, R.F., van den Berg, O., Nguyen, L.T.T., Fehér, K. and Du Prez, F.E. (2014) Microencapsulation of Active Ingredients Using PDMS as Shell Material. Macromolecules, 47, 8231-8237. https://doi.org/10.1021/ma501897j

[74] Anal, A.K. and Singh, H. (2007) Recent Advances in Microencapsulation of Probiotics for Industrial Applications and Targeted Delivery. Trends in Food Science \& Technology, 18, 240-251. https://doi.org/10.1016/j.tifs.2007.01.004

[75] Skelbaek, T. and Andersen, S. (1994) WO94/01001.

[76] Oxley, J.D. (2012) Spray Cooling and Spray Chilling for Food Ingredient and Nutraceutical Encapsulation. In: Garti, N. and McClements, D.J., Eds., Encapsulation Technologies and Delivery Systems for Food Ingredients and Nutraceuticals, Woodhead Publishing, Sawston, Cambridge, 110-130.

https://doi.org/10.1533/9780857095909.2.110

[77] Favaro-Trindade, C.S., Okuro, P.K. and Matos, J.F.E. (2015) Encapsulation via Spray Chilling/Cooling/Congealing. In: Mishra, M., Ed., Handbook of Encapsulation and Controlled Release, CRC Press, Boca Raton, 71-88.

[78] Desai, K.G.H. and Park, H.J. (2005) Recent Developments in Microencapsulation of Food Ingredients. Drying Technology, 23, 1361-1394.

https://doi.org/10.1081/DRT-200063478

[79] Nedovic, V.A., Obradovic, B., Leskosek-Cukalovic, I. and Vunjak-Novakovic, G. (2001) Immobilized Yeast Bioreactor Systems for Brewing-Recent Achievements. In: Hofman, M. and Thonart, P., Eds., Engineering and Manufacturing for Biotechnology, Springer, Dordrecht, 277-292. https://doi.org/10.1007/0-306-46889-1_18

[80] Schlameus, W. (1995) Centrifugal Extrusion Encapsulation. In: Risch, S.J. and Reineccius, G.A., Eds., Encapsulation and Controlled Release of Food Ingredients. ACS Symposium Series, Vol. 590, ACS Publications, Washington DC, 96-103. https://doi.org/10.1021/bk-1995-0590.ch009

[81] Saleeb, F.Z. and Arora, V.K. (1999) US5972395. 
[82] Anandharamakrishnan, C. and Ishwarya, S.P. (2015) Spray Drying Techniques for Food Ingredient Encapsulation. John Wiley \& Sons, Ltd., Hoboken. https://doi.org/10.1002/9781118863985

[83] Shade, C.W. (2016) Liposomes as Advanced Delivery Systems for Nutraceuticals. Integrative Medicine: A Clinician's Journal, 15, 33-36. https://www.ncbi.nlm.nih.gov/pmc/articles/PMC4818067/pdf/33-36.pdf

[84] Kirby, C.J.,Whittle, C.J., Rigby, N., Coxon, D.T. and Law, B.A. (1991) Stabilization of Ascorbic Acid by Microencapsulation. International Journal of Food Science and Technology, 26, 437-449. https://doi.org/10.1111/j.1365-2621.1991.tb01988.x

[85] Benech, R.O., Kheadr, E.E., Laridi, R., Lacroix, C. and Fliss, I. (2002) Inhibition of Listeria innocua in Cheddar Cheese by Addition of Nisin Z in Liposomes or by in Situ Production in Mixed Culture. Applied and Environmental Microbiology, 68, 3683-3690. https://doi.org/10.1128/AEM.68.8.3683-3690.2002

[86] Kheadr, E.E., Vuillemard, J.C. and El Deeb, S.A. (2000) Accelerated Cheddar Cheese Ripening with Encapsulated Proteinases. International Journal of Food Science and Technology, 35, 483-495. https://doi.org/10.1046/j.1365-2621.2000.00398.x

[87] Zheng, S., Alkan-Onyuksel, H., Beissinger, R.L. and Wasan, D.T. (1999) Liposome Microencapsulation without Using Any Organic Solvent. Journal Dispersion Science and Technology, 20, 1189-1203. https://doi.org/10.1080/01932699908943844

[88] Maa, Y.F. and Hsu, C. (1999) Performance of Sonication and Microfluidization for Liquid-Liquid Emulsification. Pharmaceutical Development and Technology, 4, 233-240. https://doi.org/10.1081/PDT-100101357

[89] Eratte, D., Wang, B., Dowling, K., Barrow, C.J. and Adhikari, B.P. (2014) Complex Coacervation with Whey Protein Isolate and Gum Arabic for the Microencapsulation of Omega-3 Rich Tuna Oil. Food \& Function, 5, 2743-2750. https://doi.org/10.1039/C4FO00296B

[90] Zhang, W., Yan, C., May, J. and Barrow, C.J. (2009) Whey Protein and Gum Arabic Encapsulated Omega-3 Lipids: The Effect of Material Properties on Coacervation. Agro Food Industry Hi-Tech, 20, 20-23.

http://dro.deakin.edu.au/view/DU:30019661

[91] Stainsby, G. (1980) Proteinaceous Gelling Systems and Their Complexes with Polysaccharides. Food Chemistry, 6, 3-14.

https://doi.org/10.1016/0308-8146(80)90003-5

[92] Pagington, J.S. (1986) $\beta$-Cyclodextrin and Its Uses in the Flavour Industry. In: Birch, G.G. and Lindley, M.G., Eds., Developments in Food Flavours, Elsevier Applied Science, London.

[93] Dziezak, J.D. (1998) Microencapsulation and Encapsulated Food Ingredients. Food Technology, 42, 136-151.

[94] Yuliani, S., Bhandari, B., Rutgers, R. and D’Arcy, B. (2004) Application of Microencapsulated Flavor to Extrusion Product. Food Review International, 20, 163-185. https://doi.org/10.1081/FRI-120037159

[95] Hu, B., Pan, C., Sun, Y., Hou, Z., Ye, H., Hu, B. and Zeng, X. (2008) Optimization of Fabrication Parameters to Produce Chitosan-Tripolyphosphate Nanoparticles for Delivery of Tea Catechins. Journal of Agricultural and Food Chemistry, 56, 7451-7458. https://doi.org/10.1021/jf801111c

[96] Han, J., Guenier, A.-S., Salmieri, S. and Lacroix, M. (2008) Alginate and Chitosan Functionalization for Micronutrient Encapsulation. Journal of Agricultural and Food Chemistry, 56, 2528-2535. https://doi.org/10.1021/jf703739k 
[97] Thies, C. (2000) Microencapsulation Kirk-Othmer Encyclopedia of Chemical Technology. John Wiley \& Sons, Inc., Hoboken. https://doi.org/10.1002/0471238961.1309031820080905.a01

[98] Zhang, Y. and Rochefort, D. (2012) Characterisation and Applications of Microcapsules Obtained by Interfacial Polycondensation. Journal of Microencapsulation, 29, 636-649. https://doi.org/10.3109/02652048.2012.676092

[99] Chan, E.S. and Zhang, Z. (2005) Bioencapsulation by Compression Coating of Probiotic Bacteria for Their Protection in an Acidic Medium. Process Biochemistry, 40, 3346-3351. https://doi.org/10.1016/j.procbio.2005.03.001

[100] Yeo, Y. and Park, K. (2004) A New Microencapsulation Method Using an Ultrasonic Atomizer Based on Interfacial Solvent Exchange. Journal of Controlled Release, 100, 379-388. https://doi.org/10.1016/j.jconrel.2004.09.012

[101] Wandrey, C., Bartkowiak, A. and Harding, S.E. (2010) Materials for Encapsulation. In: Zuidam, N.J. and Nedović, V.A., Eds., Encapsulation Technologies for Active Food Ingredients and Food Processing, Springer, New York, 31-100. https://doi.org/10.1007/978-1-4419-1008-0_3

[102] Jafari, S.M., Assadpoor, E., He, Y. and Bhandari, B. (2008) Encapsulation Efficiency of Food Flavours and Oils during Spray Drying. Drying Technology, 26, 816-835. https://doi.org/10.1080/07373930802135972

[103] King, W., Trubiano, P. and Perry, P. (1976) Modified Starch Encapsulating Agents Offer Superior Emulsification, Film Forming, and Low Surface Oil. Food Product Development, 10, 54-57.

[104] Drusch, S., Serfert, Y. and Schwarz, K. (2006) Microencapsulation of Fish Oil with n-Octenylsuccinate-Derivatised Starch: Flow Properties and Oxidative Stability. European Journal of Lipid Science and Technology, 108, 501-512. https://doi.org/10.1002/ejlt.200500312

[105] Jeon, Y.J., Vasanthan, T., Temelli, F. and Song, B.K. (2003) The Suitability of Barley and Corn Starches in Their Native and Chemically Modified Forms for Volatile Meat Flavor Encapsulation. Food Research International, 36, 349-355. https://doi.org/10.1016/S0963-9969(02)00226-0

[106] Trubiano, P.C. and Lacourse, N.L. (1988) Emulsion-Stabilising Starches: Use in Flavor. In: Risch, S.J. and Reineccius, G.A., Eds., Flavor Encapsulation, American Chemical Society, Washington DC, 45-54.

https://doi.org/10.1021/bk-1988-0370.ch006

[107] Bertolini, A.C., Siani, A.C. and Grosso, C.R.F. (2001) Stability of Monoterpenes Encapsulated in Gum Arabic by Spray-Drying. Journal of Agricultural and Food Chemistry, 49, 780-785. https://doi.org/10.1021/jf000436y

[108] Gascon, A.D., Zuritz, C.A., Bustamante, J.A., Borbon, L.D. and Oberti, G. (2001) A Study of Different Formulations of Wall Support Systems for Microencapsulation of Antioxidant Essential Oils. ISHS Acta Horticulturae, 503, 53-58.

[109] Fang, X., Shima, M. and Adachi, S. (2005) Effects of Drying Conditions on the Oxidation of Linoleic Acid Encapsulated with Gum Arabic by Spray-Drying. Food Science and Technology Research, 11, 380-384. https://doi.org/10.3136/fstr.11.380

[110] McNamee, B.F., O'Riordan, E.D. and O’Sullivan, M. (2001) Effect of Partial Replacement of Gum Arabic with Carbohydrates on Its Microencapsulation Properties. Journal of Agricultural and Food Chemistry, 49, 3385-3388. https://doi.org/10.1021/jf001003y

[111] Minemoto, Y., Hakamata, K., Adachi, S. and Matsuno, R. (2002) Oxidation of Linoleic 
Acid Encapsulated with Gum Arabic or Maltodextrin by Spraydrying. Journal of Microencapsulation, 19, 181-189. https://doi.org/10.1080/02652040110065468

[112] Beristain, C.I., Garcia, H.S. and Vernon-Carter, E.J. (1999) Mesquite Gum (Prosopis juliflora) and Maltodextrin Blends as Wall Materials for Spray-Dried Encapsulated Orange Peel Oil. Food Science and Technology International, 5, 353-356.

https://doi.org/10.1177/108201329900500408

[113] Bhandari, B.R., D’Arcy, B.R. and Bich, L.L.T. (1998) Lemon Oil to Beta-Cyclodextrin Ratio Effect on the Inclusion Efficiency of Beta-Cyclodextrin and the Retention of Oil Volatiles in the Complex. Journal of Agricultural and Food Chemistry, 46, 1494-1499. https://doi.org/10.1021/jf970605n

[114] Bhandari, B.R., D’Arcy, B.R. and Padukka, I. (1999) Encapsulation of Lemon Oil by Paste Method Using Beta-Cyclodextrin: Encapsulation Efficiency and Profile of Oil Volatiles. Journal of Agricultural and Food Chemistry, 47, 5194-5197. https://doi.org/10.1021/jf9902503

[115] Chan, L.W., Lim, L.T. and Heng, P.W.S. (2000) Microencapsulation of Oils Using Sodium Alginate. Journal of Microencapsulation, 17, 757-766. https://doi.org/10.1080/02652040050161747

[116] Bustos, R., Romo, L., Yanez, K., Diaz, G. and Romo, C. (2003) Oxidative Stability of Carotenoid Pigments and Polyunsaturated Fatty Acids in Microparticulate Diets Containing Krill Oil for Nutrition of Marine Fish Larvae. Journal of Food Engineering, 56, 289-293. https://doi.org/10.1016/S0260-8774(02)00272-8

[117] Timilsena, Y.P., Wang, B., Adhikari, R. and Adhikari, B. (2016) Preparation and Characterization of Chia Seed Protein Isolate-Chia Seed Gum Complex Coacervates. Food Hydrocolloids, 52, 554-563. https://doi.org/10.1016/j.foodhyd.2015.07.033

[118] Kaushik, P., Dowling, K., McKnight, S., Barrow, C.J. and Adhikari, B. (2016) Microencapsulation of Flaxseed Oil in Flaxseed Protein and Flaxseed Gum Complex Coacervates. Food Research International, 86, 1-8. https://doi.org/10.1016/j.foodres.2016.05.015

[119] Bylaite, E., Venskutonis, P.R. and Mapdpieriene, R. (2001) Properties of Caraway (Carum carvi L.) Essential Oil Encapsulated into Milk Proteinbased Matrices. European Food Research and Technology, 212, 661-670. https://doi.org/10.1007/s002170100297

[120] Li, J.K., Wang, N. and Wu, X.S. (1998) Gelatin Nanoencapsulation of Protein/Peptide Drugs Using an Emulsifier-Free Emulsion Method. Journal of Microencapsulation, 15, 163-172. https://doi.org/10.3109/02652049809006846

[121] Kim, Y.D., Morr, C.V. and Schenz, T.W. (1996) Microencapsulation Properties of Gum Arabic and Several Food Proteins: Liquid Orange Oil Emulsion Particles. Journal of Agricultural and Food Chemistry, 44, 1308-1313. https://doi.org/10.1021/jf950391e

[122] Jimenez, M., Garcia, H.S. and Beristain, C.I. (2004) Spray-Drying Microencapsulation and Oxidative Stability of Conjugated Linoleic Acid. European Food Research and Technology, 219, 588-592. https://doi.org/10.1007/s00217-004-0992-4

[123] McClements, D.J. (2004) Protein-Stabilized Emulsions. Current Opinion in Colloid \& Interface Science, 9, 305-313. https://doi.org/10.1016/j.cocis.2004.09.003

[124] Damodaran, S. (2005) Protein Stabilization of Emulsions and Foams. Journal of Food Science, 70, R54-R66. https://doi.org/10.1111/j.1365-2621.2005.tb07150.x

[125] Sheu, T.Y. and Rosenberg, M. (1998) Microstructure of Microcapsules Consisting of 
Whey Proteins and Carbohydrates. Journal of Food Science, 63, 491-494. https://doi.org/10.1111/j.1365-2621.1998.tb15770.x

[126] Keogh, M.K., O’Kennedy, B.T., Kelly, J., Auty, M.A., Kelly, P.M., Fureby, A. and Haahr, A.M. (2001) Stability to Oxidation of Spray-Dried Fish Oil Powder Microencapsulated Using Milk Ingredients. Journal of Food Science, 66, 217-224. https://doi.org/10.1111/j.1365-2621.2001.tb11320.x

[127] Fathi, M., Mozafari, M.R. and Mohebbi, M. (2012) Nanoencapsulation of Food Ingredients Using Lipid Based Delivery Systems. Trends in Food Science \& Technology, 23, 13-27. https://doi.org/10.1016/j.tifs.2011.08.003

[128] Kaushik, P., Dowling, K., Barrow, C.J. and Adhikari, B. (2015) Complex Coacervation between Flaxseed Protein Isolate and Flaxseed Gum. Food Research International, 72, 91-97. https://doi.org/10.1016/j.foodres.2015.03.046

[129] Carneiro, H.C., Tonon, R.V., Grosso, C.R. and Hubinger, M.D. (2013) Encapsulation Efficiency and Oxidative Stability of Flaxseed Oil Microencapsulated by Spray Drying Using Different Combinations of Wall Materials. Journal of Food Engineering, 115, 443-451. https://doi.org/10.1016/j.jfoodeng.2012.03.033

[130] Wang, B., Adhikari, B. and Barrow, C.J. (2014) Optimisation of the Microencapsulation of Tuna Oil in Gelatin-Sodium Hexametaphosphate Using Complex Coacervation. Food Chemistry, 158, 358-365.

https://doi.org/10.1016/j.foodchem.2014.02.135

[131] Pothakamury, U.R. and Barbosa-Cánovas, G.V. (1995) Fundamental Aspects of Controlled Release in Foods. Trends in Food Science \& Technology, 6, 397-406. https://doi.org/10.1016/S0924-2244(00)89218-3

[132] Vongsvivut, J., Heraud, P., Zhang, W., Kralovec, J.A., McNaughton, D. and Barrow, C.J. (2012) Quantitative Determination of Fatty Acid Compositions in Micro-Encapsulated Fish-Oil Supplements Using Fourier Transform Infrared (FTIR) Spectroscopy. Food Chemistry, 135, 603-609. https://doi.org/10.1016/j.foodchem.2012.05.012

[133] Barrow, C.J., Nolan, C. and Jin, Y. (2007) Stabilization of Highly Unsaturated Fatty Acids and Delivery into Foods. Lipid Technology, 19, 108-111. https://doi.org/10.1002/lite.200600037

[134] Ducel, V., Richard, J., Popineau, Y. and Boury, F. (2004) Adsorption Kinetics and Rheological Interfacial Properties of Plant Proteins at the Oil-Water Interface. Biomacromolecules, 5, 2088-2093. https://doi.org/10.1021/bm049739h

[135] Wang, B., Li, D., Wang, L.J., Adhikari, B. and Shi, J. (2010) Ability of Flaxseed and Soybean Protein Concentrates to Stabilize Oil-in-Water Emulsions. Journal of Food Engineering, 100, 417-426. https://doi.org/10.1016/j.jfoodeng.2010.04.026

[136] Wang, B., Wang, L.J., Li, D., Adhikari, B. and Shi, J. (2011) Effect of Gum Arabic on Stability of Oil-in-Water Emulsion Stabilized by Flaxseed and Soybean Protein. Carbohydrate Polymers, 86, 343-351. https://doi.org/10.1016/j.carbpol.2011.04.059 